\title{
A construção da Base Nacional Comum Curricular na mídia: que atores e posições foram veiculados pelo jornal Folha de São Paulo?
}

\author{
Pricila de Fátima Stankevecz* \\ Noela Invernizzi Castillo**
}

\begin{abstract}
Resumo
Este artigo visa identificar os atores e temas em debate em torno da Base Nacional Comum Curricular (BNCC) no jornal Folha de São Paulo. Para isso, examinamos as matérias sobre a BNCC publicadas na edição online do jornal entre 1 de janeiro e 31 de dezembro de 2015, período chave na elaboração da BNCC. Este enfoque de pesquisa se justifica uma vez que a divulgação de ideias na mídia é fundamental para a discussão e aceitação de políticas públicas (SEIBEL, 2013). Os resultados mostraram um ator dominante, as fundações e ONGs empresariais, que usaram o espaço no jornal para manifestar seu apoio à BNCC.

Palavras-chave: Educação; Currículo nacional; Base Nacional Curricular Comum, fundações; ONGs.
\end{abstract}

\begin{abstract}
The goal of this article is to identify actors and themes in the debate on the National Curriculum in Brazil carried out in the newspaper Folha de São Paulo. To that end, we examined the pieces on the subject published by the online edition of the newspaper, from January 1 to December 31, 2015, a key period in the elaboration of the national curriculum. This research approach was justified since media dissemination of ideas is instrumental to the discussion and acceptance of public policies (SEIBEL, 2013). Main results show that business-supported foundations and NGOs were the dominant actor, and they used the space in the newspaper to promote the national curriculum.
\end{abstract}

Keywords: Education; National curriculum; Common National Curricular Base; foundations; NGOs.

\section{Introdução}

Examinar a construção da Base Nacional Comum Curricular (BNCC) é de fundamental relevância para a educação, não apenas porque se trata do documento que guia os caminhos a serem seguidos na educação nacional, mas também porque é precisamente no processo de sua construção, quando os debates e as controvérsias estão em aberto, que se revelam de forma mais nítida os interesses e perspectivas dos diversos setores sociais que se posicionam sobre o projeto de educação do país.

O objetivo deste trabalho é identificar os atores e temas em debate em torno da construção da BNCC mediante uma pesquisa hemerográfica, partindo da perspectiva de que a divulgação na mídia é fundamental para a discussão e aceitação de políticas públicas (SEIBEL, 2013). A pesquisa examina as matérias sobre a BNCC publicadas no jornal Folha de São Paulo, na edição online (folha.com) no período de 1 de janeiro à 31 de dezembro de 2015. Quanto à escolha da mídia, ela se deve ao grande número de leitores (acessos) desse jornal, mas também porque consideramos que esse particular veículo da mídia impressa, ao dedicar considerável espaço ao assunto, se instituiu

\footnotetext{
*Endereço eletrônico: pricilastankevecz@ hotmail.com

***Endereço eletrônico: noela.invernizzi@ gmail.com
}

como um ator importante na promoção do debate sobre a BNCC, constituindo um ativo formador de opinião pública sobre a matéria.

A pesquisa partiu das seguintes perguntas: Quais as foram as perspectivas sobre a BNCC publicadas pela Folha de São Paulo? Quais foram os principais atores cujas visões sobre o campo do currículo e da educação foram divulgadas? A que segmentos da sociedade pertencem esses autores? Que interesses representam? Houve equilíbrio na apresentação dos pontos de vista dos diversos atores ou o jornal constituiu um formador de opinião representando interesses específicos? Quais foram os principais debates apresentados? Houve controvérsias explícitas?

Quanto ao enfoque metodológico, esta pesquisa é bibliográfica, documental e hemerográfica. Foi estruturada em três partes. A primeira parte consistiu numa revisão bibliográfica sobre o tema currículo nacional. Foi realizado um breve resgate histórico chegando ao debate recente sobre a proposta da BNCC, o qual foi abordado a partir da produção acadêmica do GT de Currículo da Associação Nacional de Pesquisa e PósGraduação em Educação (Anped).

A segunda parte da pesquisa foi de caráter documental. Foram revisadas as normativas que se 
referem ao currículo nacional a partir da Constituição de 1988, sendo estas identificadas a partir da revisão de literatura e de buscas no portal no Ministério da Educação.

A terceira parte consistiu numa pesquisa hemerográfica, um tipo particular de pesquisa documental que utiliza como fonte de dados os escritos publicados em meios de comunicação, como jornais e revistas (TENA; RIVAS-TORRES, 2007). Segundo Seibel (2013), a pesquisa hemerográfica consiste no estudo de fenômenos sociais e políticos, tomando como base publicações em jornais. Os jornais são meios de comunicação de visibilidade pública que expressam interesses e conflitos e que podem influenciar a opinião pública, podendo provocar mudanças nos posicionamentos e interesses públicos, resultando fundamentais na divulgação e aceitação de políticas públicas.

Para tanto, foi realizado um levantamento de todos os artigos publicados sobre a BNCC durante o ano de 2015. Esta delimitação temporal se justifica dado que foi o período em que ocorreu parte substancial da formulação do documento inicial, que foi posto em consulta pública pelo Ministério da Educação, o que deu lugar a grande repercussão do assunto no país através da mídia. A busca foi realizada na edição online do jornal Folha.com, utilizando as seguintes palavras chave na ferramenta de busca disponível no próprio site do jornal: currículo nacional e base nacional comum. Da primeira palavra-chave resultaram 19 notícias e, da segunda, 37 notícias, totalizando 56 matérias. Todas as matérias identificadas estão referenciadas no Anexo localizado no final do texto. A informação de conteúdo foi sistematizada elaborando, para cada matéria, uma ficha contendo as seguintes informações: data, título, autor ou ator ${ }^{1}$, vinculação profissional do autor, categoria (seção em que aparece o artigo: editorial, coluna, opinião, cotidiano, educação, etc.), atores citados no artigo, argumentos principais, palavras chave sobre $o$ conteúdo. Essas informações foram organizadas numa planilha Excel.

Posteriormente, foi realizada uma análise de conteúdo das matérias, para identificar os argumentos e posicionamentos presentes nas matérias. Trata-se de uma técnica que permite investigar de forma sistemática o conteúdo das comunicações mediante a classificação em categorias dos conteúdos manifestos em uma dada comunicação ou mensagem (AIGENEREN, 1999).

A análise de conteúdo foi feita seguindo as três etapas sugeridas por Bardin (1977) para classificar as categorias temáticas relevantes para o objeto de pesquisa, quais sejam: a) pré-análise, organização do material a partir de uma primeira leitura e elaboração de hipóteses provisórias; b) codificação, mediante uma nova leitura do material, identificando assuntos e agrupando-os em categorias relevantes para o objeto de estudo; e c) tratamento dos resultados e interpretação, com identificação das características semelhantes ou diferentes entre os assuntos, categorização em unidades temáticas e interpretação em consonância com a revisão de literatura.

O artigo está organizado em quatro seções, além da introdução que apresenta de modo geral o problema, objetivos gerais e a metodologia empregada. Na seção II, a partir de revisão de literatura e de documentos apresentamos a BNCC como construção histórica que vem sendo pautada desde a década de 1980 em documentos oficiais, mas somente em 2014 se torna um projeto de lei concreto. Também fazemos uma apresentação sucinta da BNCC, contextualizando o documento e mostrando como se organizou o processo de construção. Na seção III, realizamos uma discussão teórica sobre o assunto pautada na revisão de literatura, em particular na produção científica do GT de Currículo da ANPED. Na seção IV analisamos as matérias do jornal Folha de São Paulo, publicadas no ano de 2015, sobre o tema da BNCC. A partir dessas informações levantamos os principais posicionamentos dos autores e dos atores.

Finalizamos o artigo com algumas considerações finais ressaltando que o jornal priorizou as perspectivas sobre o currículo nacional defendidas por fundações vinculadas a empresas e bancos e por organizações não governamentais, assim como a divulgação de experiências de sucesso internacionais. Estes atores mais visíveis confluíram em afirmar as melhorias e progressos que um currículo nacional poderá trazer para a qualidade da educação no país.

\section{O processo de construção do currículo nacional}

Desde a implementação do Plano Nacional de Educação (PNE), em 2014, ganha força o movimento para construção de um Currículo Nacional, que recebe o título de Base Nacional Comum Curricular. No entanto, a formulação de um currículo nacional já havia sido pautada em outros momentos históricos, como uma necessidade para homogeneizar o sistema educacional brasileiro. $\mathrm{Na}$ década de 1980 a questão foi abordada no contexto 
da redemocratização do país. A Constituição Federal de 1988 (BRASIL, 1988) traçou direcionamentos sobre um currículo nacional e, posteriormente, foram retomados na Lei de Diretrizes e Bases da Educação Nacional de 1996 (BRASIL, 2010). Todavia, uma aproximação mais concreta ocorreu apenas em 2014 com a formulação do PNE (BRASIL, 2014a), e em 2015, com a elaboração da primeira versão da BNCC (BRASIL, 2015), objeto de nossa análise.

Segundo Moreira (2000), no Brasil, desde a década de 1980, com a queda do regime militar e a crescente redemocratização da sociedade, viu-se a necessidade de repensar o quê ensinar, como ensinar e como fazer com que as classes menos favorecidas tivessem acesso a uma escola de qualidade. Tendo em vista uma alta taxa de evasão registrada na época, o currículo ganhou importância, sendo considerado essencial para a mudança da escola. Outra grande questão indagada na época foi como fazer com que esse currículo realmente chegasse às salas de aula. Ambas as questões ainda hoje são cruciais. Nesse momento, as duas abordagens predominantes sobre o currículo foram as da pedagogia crítico-social de Demerval Saviani, e da pedagogia social ou educação popular de Paulo Freire. As duas linhas de pensamento buscavam o mesmo fim: uma educação de qualidade para todos, porém se diferenciavam nas suas propostas. Enquanto a primeira colocava a ênfase em democratizar e fazer chegar às classes trabalhadoras a bagagem do conhecimento humano (o que pode ser visto como uma perspectiva de conhecimento universal), a segunda propunha um enfoque de conhecimentos mais situados, organizados a partir de temas geradores, surgidos do contexto e necessidades dos alunos (SILVA, 1999). A expectativa era que essas novas propostas curriculares contribuíssem para resolver os desafios educacionais da época. Contudo, como coloca Moreira (2000), as mudanças não foram muito significativas, e com isso o país chegou à década de 1990 com taxas de evasão e repetência ainda muito altas.

Já na década de 1990 as influências mais significativas nos enfoques curriculares foram o pós-modernismo e o pós-estruturalismo, ambos enfatizando a questão da diversidade cultural, étnico-racial e de gênero. $O$ currículo baseado nestas abordagens tende a se opor à ideia de currículo nacional, por entender que este último padroniza, enquanto o aspecto ressaltado é a diversidade cultural. Porém, para Moreira (2000), toda essa diversidade curricular proposta não foi suficiente para abarcar as especificidades do contexto brasileiro e a teorização pós-crítica nas propostas curriculares limitou-se a algumas sugestões sobre multiculturalismo, gênero e sexualidade. Junto a estas novas abordagens, sustenta $\mathrm{o}$ autor, permaneceu ainda forte a influência da pedagogia crítica nas reformas curriculares realizadas, que pretendiam desafiar o caráter centralizador das propostas do MEC.

Ainda para Moreira (2000), houve, no mesmo período, um grande esforço por parte do Governo Federal para difundir os Parâmetros Curriculares Nacionais (PCN), numa tentativa de indicar conteúdos básicos para a educação em todo o país, embora de forma não obrigatória. Os PCN propunham um conteúdo básico comum, organizado em disciplinas tradicionais, e introduziram os temas transversais como ferramenta para abordar questões de diversidade numa perspectiva interdisciplinar, embora de maneira pouco estruturada (MACEDO, 1988). Então, a partir dos PCN, surgiram currículos que tentaram, de diversas formas, implantar abordagens interdisciplinares nos eixos transversais e norteadores, nos princípios educativos e nos núcleos conceituais. Este documento, apesar de conter um caráter padronizador, não tinha caráter obrigatório, de modo que cada escola tinha liberdade para definir seus conteúdos e metodologias. Mais ainda, como salienta Moreira (2000) houve espaços para reação aos PCN e durante a década de 1990 vários formatos alternativos de currículos foram elaborados no país.

Nesse mesmo momento, as avaliações padronizadas ou em larga escala passaram a ser parte da política educacional do Estado que, mediante esse instrumento passou a fortalecer sua ação regulatória sobre os conteúdos ensinados, assim como o poder simbólico e operacional do governo (ABREU; SILVA, 2008). A implementação do sistema de avaliação esteve vinculada a outros programas de governo, no bojo das reformas neoliberais da década de 90, como o Programa Brasileiro de Qualidade e Produtividade (PBQP), do governo Collor, que estabelecia a necessidade de formular uma política educacional que tivesse como eixo a educação para a competitividade. Ainda segundo as autoras, o programa incorporou muitas orientações que foram difundidas pela UNESCO e pelo Banco Mundial, sendo uma delas o sistema de avaliação. Configurou-se, então, um projeto de formação baseado nos PCN e um processo de avaliação que deveria elevar os indicadores de 
qualidade do processo de ensino-aprendizagem, tendo os exames nacionais como forma de controle do Estado sobre o que estava sendo ensinado.

Os exames padronizados indicam qual conhecimento é relevante, delimitando assim o que deve ou não ser ensinado nas escolas. Os sistemas de avaliação funcionam como "mecanismos do Estado para regular os currículos escolares" (SCHNEIDER, 2013, p. 18). Além de fornecer um conjunto de informações sobre o sistema educativo, as avaliações em larga escala são estratégias do Estado para manter o controle sobre a educação e manter padrões estabelecidos por suas políticas educacionais. Nesse cenário, o currículo e o trabalho docente são instrumentos essenciais, sobre os quais se assenta a responsabilidade pelos resultados.

A implementação do Sistema Nacional de Avaliação Básica (SAEB) foi gestada na década de 80 , mas somente no final da década de 90 foi posto em prática junto com a primeira prova do ENEM e, desde então, surgiram avaliações para todas as etapas da educação básica. Esses exames funcionam como "descritores de desempenho" em um processo de aferição dos níveis cognitivos dos alunos (ABREU; SILVA. 2008). Embora, a princípio, o intuito fosse garantir a qualidade da educação, seu principal efeito foi a pressão sobre os docentes, que passaram a ensinar visando o desempenho em testes e exames, mais do que na construção do conhecimento para uma formação integral.

O país tem passado por diversas tentativas de mudar o sistema educacional por meio do currículo, dos sistemas de avaliação, da formação de professores e de novas políticas educacionais nas últimas décadas. Em 2014, com a instituição do PNE, deu-se um passo significativo que, no campo do currículo, culminou com a proposta da BNCC.

$\mathrm{O}$ projeto BNCC foi proposto pelo MEC, cristalizando um processo que, como vimos, foi pautado progressivamente na Constituição Federal de 1988, na LDB, nos PCN e nas Diretrizes Curriculares e é justificado, em seu texto, segundo estas normativas. Considerado um pacto federativo de colaboração, o documento tem um caráter regulamentador de referência e obrigatoriedade nacional. Seguindo o processo de construção da BNCC vem sendo pautada a efetivação do Sistema Nacional de Educação (SNE), previsto na Constituição Federal de 1988, que tem como principal objetivo unificar e articular todas as dimensões da educação, no intuito de promover a equidade com qualidade na educação para todo o país (BRASIL, 2014b). A efetiva implementação de um currículo comum em escala nacional depende, assim, da instituição do SNE.

Embora exceda o período aqui analisado, é importante notar que em 20 de dezembro de 2017 a BNCC foi homologada pelo Ministro da Educação José Mendonça Filho. Sendo assim, pela primeira vez, o Brasil tem um currículo nacional obrigatório para educação infantil e ensino fundamental. A partir deste documento, o MEC deve iniciar o processo de formação e capacitação dos profissionais da educação e a reformulação dos cursos de licenciatura. Os sistemas estaduais e municipais de educação deverão proceder a elaborar adequações nos seus currículos atendendo a BNCC.

\section{Posicionamentos sobre um currículo nacional}

O documento da BNCC foi exposto pelo MEC como instrumento para um projeto democrático de sociedade mediante a redução das desigualdades regionais nas oportunidades educacionais. Esta perspectiva vem sendo apoiada por vários grupos de elite no país, como empresários, organizações não governamentais e fundações financiadas por grandes empresas, que promovem a BNCC como forma de garantir o direito à aprendizagem. Nessa perspectiva, a vulnerabilidade social é considerada a principal causa da não aprendizagem, gerando um ciclo de exclusão e pobreza (CÓSSIO, 2014).

Para Macedo (2015), a formulação do currículo comum é mais que uma disputa de classes, na qual alguns sujeitos são privilegiados, e se torna uma disputa do Estado pelo controle da educação. Com a instituição da BNCC, a qualidade da educação está vinculada com o controle do que será ensinado e aos resultados obtidos nas avaliações. Da mesma forma, Gabriel (2015) avalia este processo como um movimento de centralização curricular na busca de uma cultura escolar comum. Para a autora, o currículo nacional está sendo fixado e imposto de forma engessada, em uma tentativa de centralização curricular velada por um pacto federativo, seguido de outras políticas públicas como o Sistema Nacional de Avaliação, o Sistema Nacional de Educação, a reformulação da formação inicial e continuada de professores e dos planos de carreira e a privatização dos órgãos públicos.

Discute-se se um novo documento orientador do currículo é necessário. Fernandes (2015) argumenta que não o é, pois o país já conta 
com vários outros documentos; para ele o que é necessário é fazer com que esses documentos realmente cheguem às instituições. A autora critica a proposta, pois denota uma ideologia meritocrática inserida no sistema de avaliações em larga escala e nas premiações para os sujeitos e as escolas o que, na sua perspectiva, se contrapõe com superar as desigualdades profundas do país. Da mesma forma, Barreiros (2017) pontua que a BNCC vem marcada pela meritocracia, podendo vir a ser responsável pela exclusão de sujeitos e instituições e da diversidade de pensamento sobre o currículo. Esta nova visão de currículo traz embutida uma "lógica empresarial" (FERNANDES, 2015, p.401) segundo a qual o resultado em rankings e classificações passa a ser mais importante que o próprio processo de ensino-aprendizagem que ocorre no dia a dia das escolas.

Freitas (2014) identifica um ator relevante na reforma, que denomina de reformadores empresariais. Segundo o autor, se trata das instituições não governamentais de assessoria à educação, sejam elas internacionais ou nacionais, que trazem para o campo educacional a lógica empresarial e tecnicista de organização do trabalho pedagógico. Nesta perspectiva, argumenta que a crescente internacionalização das políticas educacionais e a forte participação dos reformadores empresariais nas propostas de reforma conduzem a um novo controle ideológico imposto pelo Estado, ajustando as escolas a um padrão cultural básico de instrução que será verificado pelos sistemas de avaliação, sejam internos ou externos. Isto, por sua vez, gera uma centralidade da avaliação escolar e uma política de responsabilização dos alunos, dos professores e das escolas, sem levar em consideração fatores sociais externos que afetam o rendimento do aluno. Para o autor, esses reformadores empresariais atuam como novos colonizadores que irão levar à população mais carente o acesso a uma "boa cultura", retirando o direito de formação ampla e contextualizada e impondo um direito de aprender o básico que será validado pelas avaliações. No fundo, trata-se novamente de adaptar a escola às exigências oriundas do mundo trabalho. Neste sentido, sustenta que

os atuais reformadores - novos colonizadores empresariais apenas retomam esta filosofia pragmatista do começo do século passado em outros níveis de exigência tecnológica e de controle social que lhe dão aparência de inovação (FREITAS, 2014, p.1105).
A esse projeto, o autor contrapõe a ideia de que uma "boa educação exige uma matriz alargada de formação que não restrinja as possibilidades de formação humana da juventude" (FREITAS, 2014, p.1107). À padronização da cultura escolar, opõe a necessidade de respeitar a diversidade cultural buscando uma formação integral.

A reforma curricular proposta, segundo Dourado (2013), terá reflexos na formação inicial e continuada dos docentes. Para o autor, a formação de professores está totalmente ligada com a prática diária, com questões culturais, identitárias, concepções teóricas, tornando-se assim um campo de disputa política. Ao se instituir a lógica dos reformadores empresariais, os docentes serão treinados para seguir apostilas e obter boas notas nas avaliações. $\mathrm{O}$ autor ainda reflete que devemos encontrar um caminho para acompanhar as mudanças da sociedade sem cair no tecnicismo, sem privatizar as instituições e principalmente sem legitimar os mecanismos de controle social que vêm sendo impostos.

$\mathrm{Na}$ perspectiva de Moreira (2000), um currículo comum significa uma forma mecânica e autoritária de organizar o ensino e, para fugirmos disso, é necessário um espaço de criatividade e liberdade para que os currículos sejam criados localmente. Sünssekind (2014), por sua vez, ressalta a incoerência de escolher o que é comum a partir do juízo de especialistas sem considerar o que foi construído histórica e localmente pelos sujeitos em interação e/ou cooperação dentro de suas diversidades. $\mathrm{O}$ comum deveria significar a valorização das diferenças na sociedade e nos currículos das escolas, mas a desvalorização destas, e a legitimação daqueles acaba reforçando as desigualdades, a exclusão, e a inadequação, gerando invisibilidade de determinadas ideias.

A BNCC está ancorada no PNE, mas o real sentido dessa proposta só pode ser entendido, conforme Silva (2015), analisando alguns conceitos como educação, formação humana, currículo e políticas curriculares, pois, afinal, a discussão de currículo não se esgota em conteúdos. A autora, refletindo a partir do ensino médio, etapa da educação que vem sendo território de disputa, considera que:

o documento produzido pelo MEC não possui suficiência no que se propõe, haja vista ter negligenciado justamente essa discussão e recaído na mais pragmática formulação: a definição de listagens de conteúdos travestidos de direitos e objetivos de aprendizagem 
(SILVA, 2015, p.366).

Para Silva (2015, p. 369), a definição de conteúdos específicos dificulta a possibilidade de o indivíduo ir além do superficial, "a experiência formativa na tradição curricular tomada como sinônimo de experimentação ou de treinamento não permite o exercício da reflexão e da crítica". Ademais, o currículo expressa também as ações por meio das quais se realiza o processo formativo no tempo-espaço da escola, um processo nem sempre circunscrito ao que está prescrito. Sendo assim, a autora argumenta que o currículo deve ser flexível e atender a todas as demandas da educação, que vão além dos conteúdos. Pelo contrario, em concordância com outros pesquisadores já citados, sustenta que a BNCC pode vir a se tornar um instrumento de controle do Estado sobre as escolas e sobre a formação dos indivíduos, reforçada pelos exames padronizados, gerando uma "formação administrada." Esse tipo de formação se contrapõe à ideia de formação crítica e emancipatória proposta pelas Diretrizes Curriculares Nacionais, e acaba indo pelo caminho oposto, não respeitando as diferenças e diversidades, como a condição social, as diferenças étnico-raciais e de gênero. Assim, reforça:

A padronização é contrária ao exercício da liberdade e da autonomia, seja das escolas, seja dos educadores, seja dos estudantes em definirem juntos o projeto formativo que alicerça a proposta curricular da escola. Nesse sentido, as Diretrizes Curriculares Nacionais exaradas pelo Conselho Nacional de Educação, dado seu caráter norteador e menos prescritivo, já não seriam suficientemente definidoras e capazes de respeitar as diferenças regionais, culturais...? (SILVA, 2015, p. 375).

A necessidade de flexibilidade combinada com certo grau de prescrição curricular sobre o que e como ensinar é defendida por Pereira (2015) como a forma mais adequada para as características do país. O autor considera que o documento deveria conter uma orientação clara dos procedimentos da gestão pedagógica democrática. Dessa forma, argumenta, estaria aberta para as escolas a possibilidade da construção de um currículo democrático via conselho escolar e planejamento político pedagógico, dentro de suas próprias especificidades.

A flexibilidade é também destacada como necessária por Macedo (2015), que considera que nem os problemas nem as soluções educacionais são estáticas, logo um currículo nacional deve ser um documento flexível e em constante (re)construção em um movimento de cooperação de baixo para cima, e não imposto de cima para baixo.

Este último ponto levantado por Macedo, a forma em que o currículo nacional foi elaborado, é outro aspecto em discussão. Pereira (2015) argumenta que a maneira hierarquizada em que está sendo construído, em que o nacional vem antes do local, definido por especialistas das diversas áreas e sendo imposto às escolas, caracteriza uma padronização e centralização da educação, deixando de lado a democracia e autonomia curricular das instituições escolares. Desta forma, para o autor, não há direitos de aprendizagem, mas a imposição vertical de um currículo baseado em conhecimentos ditos universais, sem considerar as experiências e conhecimentos locais. Assim, a BNCC anularia os direitos de aprendizagem, de democracia e de desenvolvimento cidadão dos alunos brasileiros, revelando-se como um processo autoritário que fala em democracia apenas de forma abstrata.

Nessa mesma linha, Sünssekind (2014) afirma que na discussão de um documento que se propõe orientar massas de professores, sobre o quê e como ensinar, e ser a base para a avaliação de milhões de estudantes, têm tido enorme peso organizações empresariais e financeiras que impõem seus interesses, embora de forma não explícita. Essa construção curricular acaba por reforçar a hierarquia presente na sociedade colocando professores como reprodutores de conteúdos sem levar em consideração que são profissionais-intelectuais.

\section{Atores e posicionamentos sobre a Base Nacional Comum Curricular: identificação a partir das matérias publicadas no jornal "Folha de São Paulo" em 2015}

As 56 matérias publicadas pela Folha de São Paulo durante o processo de construção da BNCC em 2015 foram publicadas em diversas seções do jornal. O maior número de publicações se concentrou na seção específica que o jornal dedica a discutir temáticas da área, "Educação", com 23 matérias. Nas seções "Cotidiano" e "Opinião" foram publicadas 12 matérias em cada uma. Resulta relevante destacar que o jornal dedicou, em 2015, quatro editoriais ao tema (incluídos na categoria "Opinião"), revelando que o assunto adotou bastante relevância na política editorial. Houve um 
número muito menor de matérias (uma ou duas) veiculadas em outras seções, como "Ilustríssima", "Painel do Leitor", etc.

As matérias foram assinadas por colaboradores da Folha, representantes do MEC, especialistas convidados, e outros atores envolvidos no processo, como mostra o Gráfico 1. Pode-se observar um lógico predomínio dos artigos escritos pelos colaboradores do jornal. Nestes encontramos jornalistas escrevendo sobre a opinião de atores envolvidos, ou realizando entrevistas, ou manifestando opinião própria. Não podemos deixar de ressaltar a participação das fundações e ONGs, que ocupam o segundo lugar em frequência entre os autores das matérias publicadas, evidenciando claro interesse em divulgar suas perspectivas na mídia. O MEC teve escassa participação direta como autor. Dada a polêmica suscitada em torno da alteração proposta na BNCC dos conteúdos da disciplina história, duas matérias tiveram autoria de historiadores, incluídos na categoria dos professores universitários.

GRÁFICO 1: Autores das matérias sobre a BNCC publicadas na Folha de São Paulo 2015

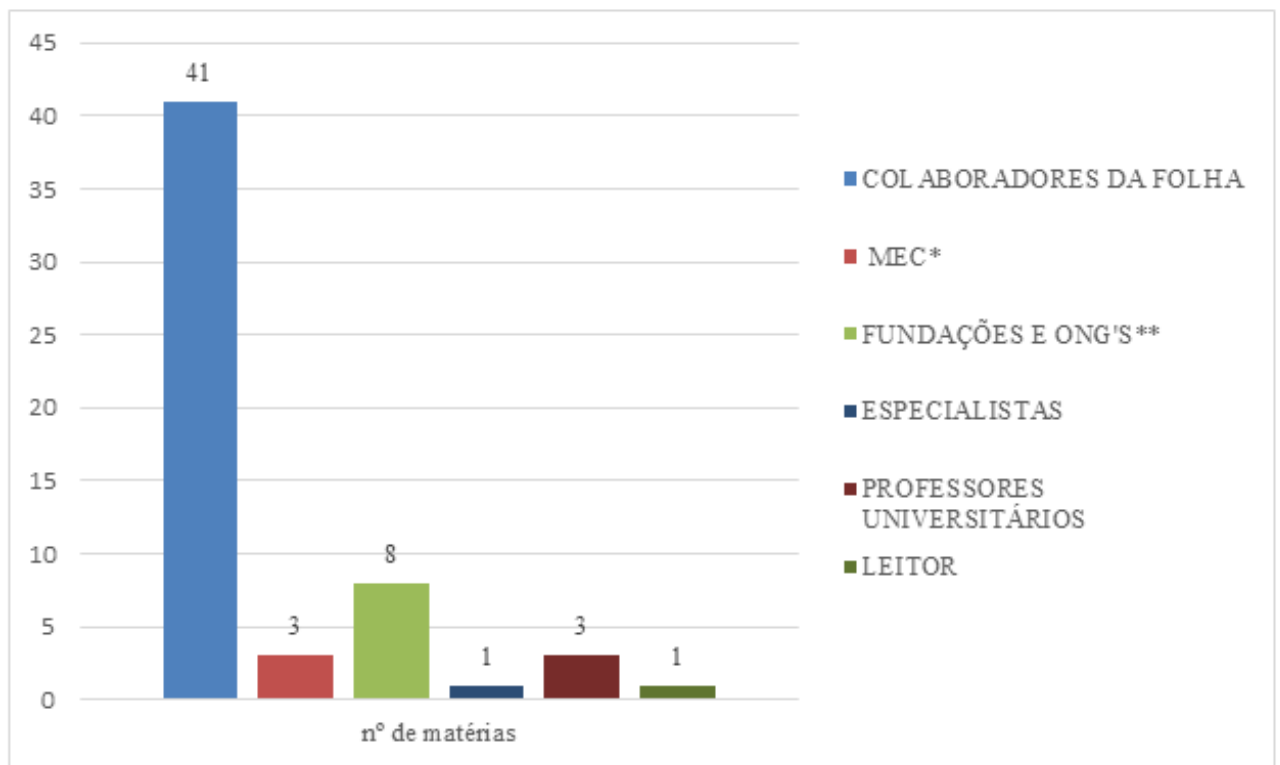

Fonte: Elaborado pelas autoras, com base na pesquisa no jornal Folha de São Paulo período de 2015.

Nota: O gráfico reporta 57 autores, uma vez que uma das matérias tem autoria de dois atores diferentes; as coautorias dentro da mesma categoria de autores (por ex. dois jornalistas) foram registradas apenas uma vez. A relação de autores e coautores pode ser vista no Anexo.

* MEC - Representado pelo Ministro em exercício em agosto de 2015, Renato Janine Ribeiro; secretários Luiz Claúdio Costa e Binho Marques; em outubro de 2015 pelo então Ministro Roberto Mangaberia Unger.

** As fundações e ONGs envolvidas são: Instituo Unibanco/Itaú Social; Todos Pela Educação; CENPEC; Fundação Lemann.

O Gráfico 2 identifica os atores citados nas matérias publicadas pelo jornal. Denominamos atores aos sujeitos ativos no processo de construção da BNCC, que foram mencionados pelo jornal em suas matérias, por meio de entrevistas, citações de opiniões e participação em eventos organizados pelo jornal, que foram relatados nas matérias. Foram citados atores em 44 matérias, enquanto 12 não fizeram referência a nenhum ator específico.

Quando atentamos para os atores observamos que a presença das fundações e ONGs com vinculação empresarial se torna expressiva, sendo citadas em 21 matérias. Chama a atenção também a citação de indivíduos apresentados como especialistas no assunto, em 17 artigos, com destaque para os especialistas estrangeiros, entre eles o australiano Barry McGaw, os britânicos Dave Peck e Michael Wilshaw, o ministro da educação sueco, Christer Tofténius, e a ministra Canadense Mary Jean Gallagher, que relatam as experiências 
com a construção e implementação do currículo nacional em seus países de origem. Estes especialistas tenderam a enfatizar a necessidade do currículo ser prescritivo. O MEC aparece citado em 13 matérias, enquanto os professores universitários em 12 matérias. Finalmente cabe destacar a ausência dos professores da educação básica que não foram, em nenhum momento, reconhecidos como atores relevantes nas matérias em torno da construção da BNCC. Assim, o jornal atribuiu maior relevância e legitimidade como fontes de informação sobre o currículo nacional a dois atores, que foram mais citados como porta-vozes do processo em curso: as fundações e ONGs e os especialistas. O próprio promotor do currículo, o MEC, e os professores universitários, tiveram menos relevância.

GRÁFICO 2: Atores citados nas matérias sobre a BNCC publicadas na Folha de São Paulo em 2015

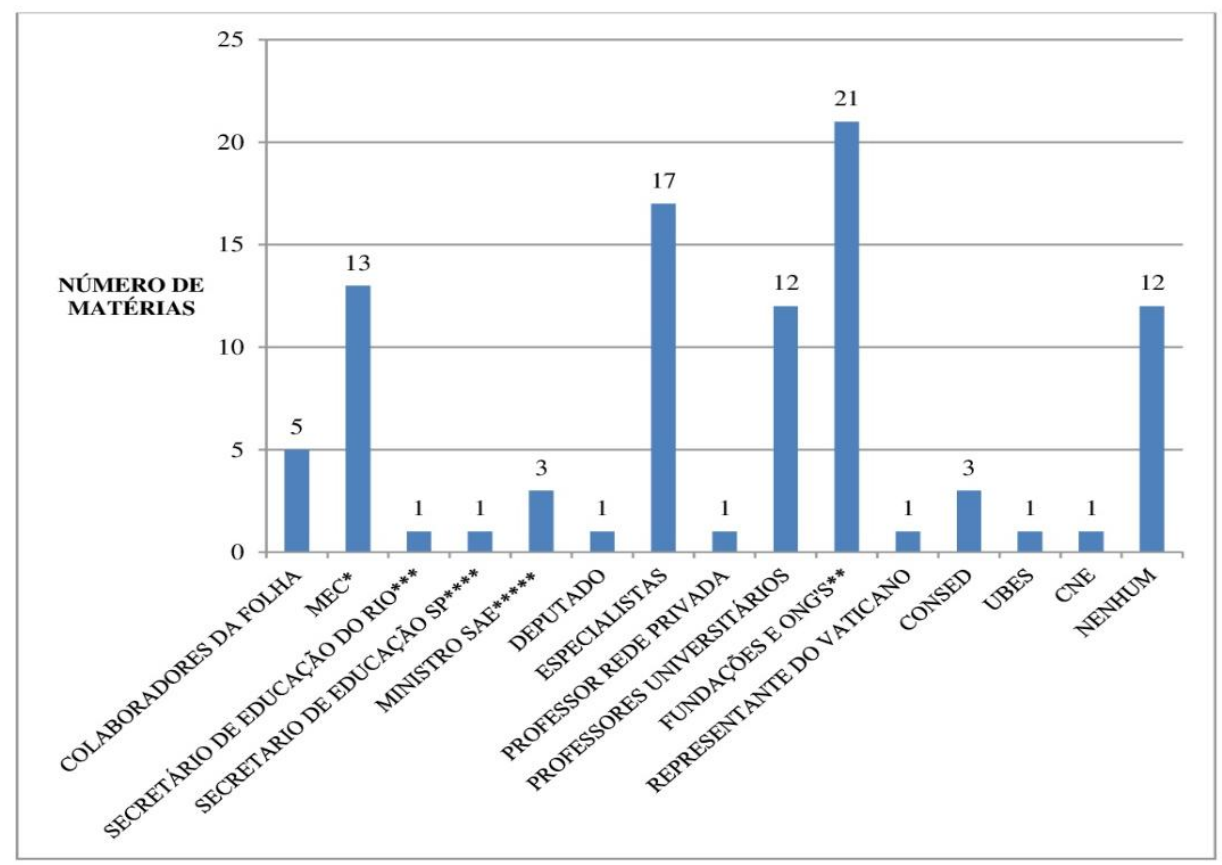

Fonte: Elaborado pelas autoras, com base na pesquisa no jornal Folha de São Paulo, período de 2015.

Nota: mais de um ator pode ser identificado em cada artigo.

* MEC - representado por Renato Janine Ribeiro - Ministro no período entre abril e setembro de 2015; Ministro Aloizio Mercadante assumiu em outubro de 2015; Secretários.

** Fundações e Organizações Não Governamentais envolvidas: Instituto Unibanco/Itaú Social; Todos Pela Educação; CENPEC; Fundação Lemann; Movimento Pela Base; CNI; INSPER; Instituto Trabalho e Sociedade; Instituo Alfa e Beto.

***Antônio Neto - Secretário de Educação do Rio de Janeiro.

**** Herman Woorwald - Secretário de Educação de São Paulo.

****** Roberto Mangabeira Unger - Ministro da Secretária de Assuntos Estratégicos.

O Gráfico 3 mostra que diversas temáticas em torno do currículo nacional foram objeto de discussão no jornal ao longo de 2015. Não apenas os autores das matérias guiaram a discussão, mas também os atores citados nelas. 
GRÁFICO 3: Temáticas em debate nas matérias sobre a BNCC publicadas pela Folha de São Paulo em 2015

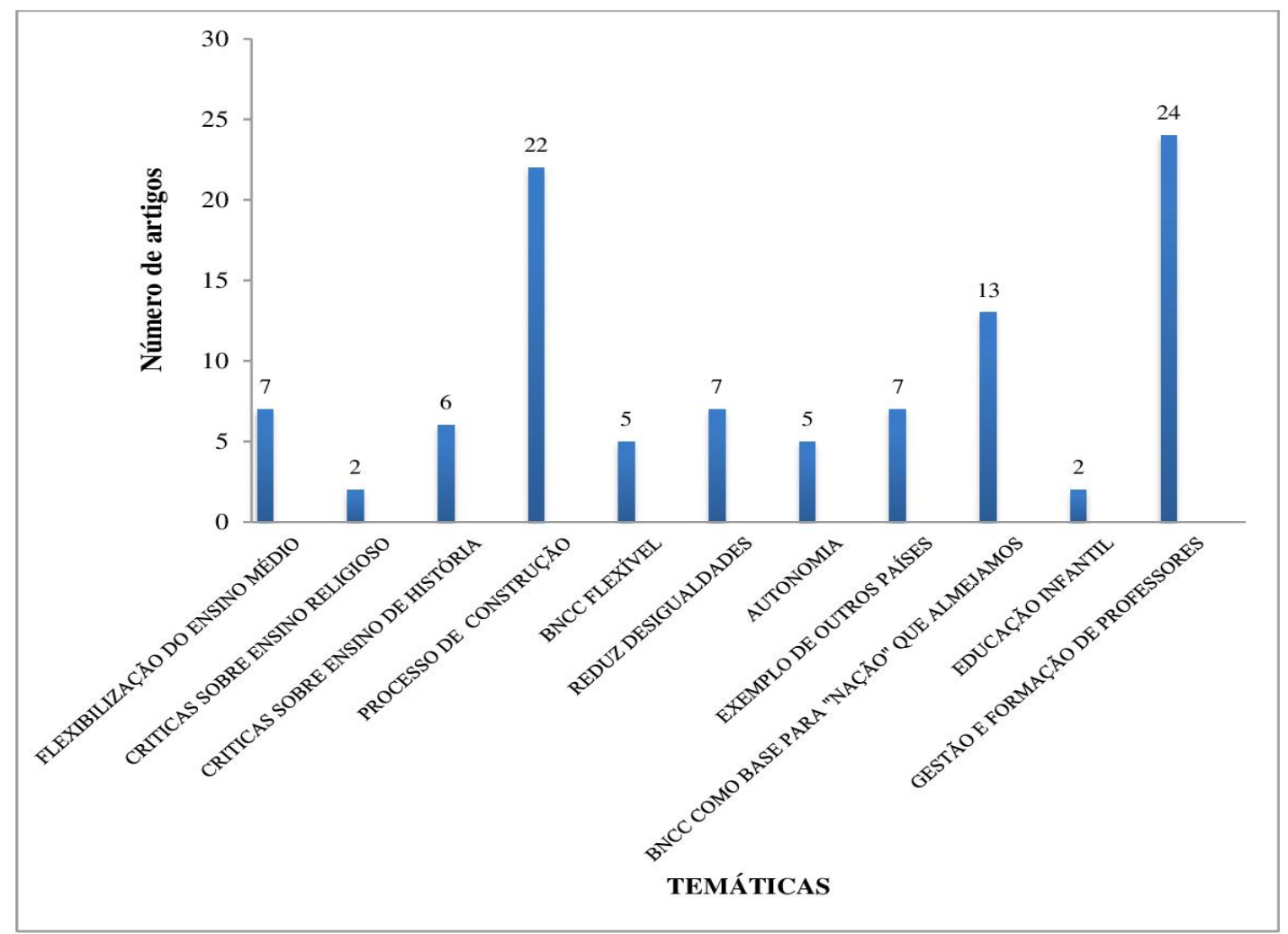

Fonte: Elaborado pelas autoras, com base na pesquisa no jornal Folha de São Paulo, período de 2015

Os dois temas de maior destaque foram a gestão e formação de professores, que aparece em 24 matérias, e o processo de construção da BCNN, tratado em 22 matérias. Segue em importância a discussão da relação entre a base curricular e o país desejado, abordada em 13 artigos. Um conjunto de temáticas fizeram sua aparição de forma mais fragmentada, tais como: flexibilização do Ensino Médio, redução de desigualdades e exemplos de outros países, críticas sobre o ensino de história, BNCC como um documento flexível e a autonomia, temas tratados entre 5 e 7 matérias cada. Por fim, com um número pouco expressivo, aparecem a Educação Infantil e as críticas sobre o ensino religioso, com apenas 2 matérias cada uma.

O Quadro 1 vincula as principais temáticas abordadas com os atores e instituições que participaram das discussões.

QUADRO 1: Relação das temáticas e atores/instituições que representam 


\begin{tabular}{|c|c|}
\hline PRINCIPAIS TEMÁTICAS & $\begin{array}{lcll}\text { ATORES } & \text { E } & \text { INSTITUIÇÕES } & \text { QUE } \\
\text { REPRESENTAM } & & \end{array}$ \\
\hline FLEXIBILIZAÇÃO DO ENSINO MÉDIO & $\begin{array}{l}\text { Renato Janine (ex ministro da educação*); Herman } \\
\text { Voorwald (secretário da educação SP****); Dave } \\
\text { Peck - Britânico (especialista); Ricardo Henriques } \\
\text { (Fundação Itáu Social); Priscila Cruz (Todos Pela } \\
\text { Educação); Roseli da Silva e Eduardo Deschamps } \\
\text { (CONSED); Bárbara Mel (UBES); Rafael } \\
\text { Lucchesi (CNI); José Lima (CNE). }\end{array}$ \\
\hline CRÍTICAS SOBRE ENSINO RELIGIOSO & $\begin{array}{l}\text { Pasto Eurico (deputado do PSD-PE); Luiz Felipe } \\
\text { Corrêa (representante do Vaticano); }\end{array}$ \\
\hline CRÍTICOS SOBRE ENSINO DE HISTÓRIA & $\begin{array}{l}\text { Renato Janine (ex ministro da educação*); } \\
\text { Demétrio Magnoli e Hélio Schwartsman } \\
\text { (colaborador do jornal); Mercadante (ministro da } \\
\text { educação**); Elaine S. Barbosa (professora } \\
\text { universitária); Silvio Freire (professor da rede } \\
\text { privada). }\end{array}$ \\
\hline PROCESSO DE CONSTRUÇÃO & $\begin{array}{l}\text { Renato Janine (ex ministro da educação*); } \\
\text { Demétrio Magnoli (colaborador do jornal); } \\
\text { Manuel Palácios(MEC); Luís Carlos Menezes, } \\
\text { Hilda Micarello (professores que representam o } \\
\text { MEC); Mercadante (ministro da educação**); } \\
\text { Roberto Mangabeira Unger (ministro SAE*****); } \\
\text { Barry McGaw-australiano, Dave Peck - britânico } \\
\text { (especialistas); Naércio Menezes Filho e Ricardo } \\
\text { Paes de Barros (INSPER); Ricardo Henrique s } \\
\text { (Fundação Itaú Social); Maria Alice Setubal e } \\
\text { Anna Helena Altenfelder (CENPEC); Denis Mizne } \\
\text { (Fundação Lemann); Cleuza Repulho (movimento } \\
\text { pela base); Luiz Alves (CNE); João Batista de } \\
\text { Oliveira (Instituto Alfa e Bato); SImom } \\
\text { Schwartzmann (Instituto de Trabalho e Sociedade). }\end{array}$ \\
\hline BNCC FLEXÍVEL & $\begin{array}{l}\text { Renato Janine (ex ministro da educação*); Binho } \\
\text { Marques e Luiz Claudio da Costa (MEC); Barry } \\
\text { McGaw-australiano (especialista); Ricardo Paes de } \\
\text { Barros (INSPER); Priscila Cruz (Todos Pela } \\
\text { Educação); Maria Alice Setubal (CENPEC); Denis } \\
\text { Mizne e Camila Pereira (Fundação Lemann); } \\
\text { Eduardo Deschamps (CONSED). }\end{array}$ \\
\hline REDUZ DESIGUALDADES & $\begin{array}{l}\text { Renato Janine (ex ministro da educação*); Hélio } \\
\text { Schwartsman (colaborador da folha); Binho } \\
\text { Marques e Luiz Claudio da Costa (MEC); Antonio } \\
\text { Neto (secretário de educação Rio***); Ricardo } \\
\text { Henriques (Fundação Itaú Social); Priscila Cruz } \\
\text { (Todos Pela Educação); Denis Mizne e Camila } \\
\text { Pereira (Fundação Lemann); }\end{array}$ \\
\hline AUTONOMIA & $\begin{array}{l}\text { Renato Janine (ex ministro da educação*); } \\
\text { Priscila Cruz (Todos Pela Educação); Cleuza } \\
\text { Repulho (movimento pela base). }\end{array}$ \\
\hline MODELO DE OUTROS PAÍSES & $\begin{array}{l}\text { Dave Peck - britânico e Barry McGaw-australiano } \\
\text { (especialista); Denis Mizne e Camila Pereira } \\
\text { (Fundação Lemann); Fábio Takahashi } \\
\text { (colaborador do jornal); Maria helena Guimarães }\end{array}$ \\
\hline
\end{tabular}




\begin{tabular}{|c|c|}
\hline & de Castro (MEC); \\
\hline $\begin{array}{l}\text { BNCC COMO PROJETO DE NAÇÃO QUE } \\
\text { ALMEJAMOS }\end{array}$ & $\begin{array}{l}\text { Binho Marques e Luiz Claudio da Costa (MEC); } \\
\text { Mercadante (ministro da educação**); Herman } \\
\text { Voorwald (secretário da educação SP****); } \\
\text { Roberto Mangabeira Unger (ministro SAE*****); } \\
\text { Dave Peck - britânico e Barry McGaw-australiano } \\
\text { (especialista); Ricardo Henriques (Fundação Itaú } \\
\text { Social); Maria Alice Setubal (CENPEC); Roseli da } \\
\text { Silva (CONSED). }\end{array}$ \\
\hline EDUCAÇÃO INFANTIL & $\begin{array}{l}\text { Christer Tofténis - suéco e Dave Peck - britânico } \\
\text { (especialista); Denis MIzne (Fundação Lemann). }\end{array}$ \\
\hline GESTÃO E FORMAÇÃO DE PROFESSORES & $\begin{array}{l}\text { Renato Janine (ex ministro da educação*); Maria } \\
\text { Helena Guimarães de Castro, Binho Marques e } \\
\text { Luiz Claudio da Costa (MEC); Mercadante } \\
\text { (ministro da educação**); Roberto Mangabeira } \\
\text { Unger (ministro SAE*****); Barry McGaw- } \\
\text { australiano (especialista); Ricardo Paes de Barros } \\
\text { (INSPER); Ricardo Henriques(Fundação Itaú } \\
\text { Social); Priscila Cruz (Todos Pela Educação); } \\
\text { Maria Alice Setubal (CENPEC); Denis Mizne e } \\
\text { Camila Pereira (Fundação Lemann). }\end{array}$ \\
\hline
\end{tabular}

Fonte: Elaborado pelas autoras, com base na pesquisa no jornal Folhacom período de 2015.

\footnotetext{
*Ministro no período entre abril e setembro de 2015, Renato Janine Ribeiro.

**Ministro Aloizio Mercadante, assumiu em outubro de 2015.

***Antônio Neto, Secretário de educação do Rio.

****Herman Woorwald, Secretário de Educação de São Paulo.

*****Ministro da Secretária de Assuntos estratégicos, Roberto Mangabeira Unger.
}

Como evidencia o Quadro 1, o jornal Folha de São Paulo repercutiu as perspectivas e posicionamentos sobre o processo de construção da BNCC de um conjunto de atores. Vários órgãos estatais, associações e organizações não governamentais estiveram envolvidos: o Conselho Nacional de Educação (CNE), a Secretária de Educação Básica (SEB), a União Nacional dos Dirigentes Municipais da Educação (UNIDIME), o Conselho Nacional de Secretários da Educação (CONSED), o Instituto Nacional de Estudos e Pesquisas Anísio Teixeira (INEP), a União Brasileira dos Estudantes Secundaristas (UBES), e organizações não governamentais como a Fundação Lemann, Confederação Nacional da Indústria (CNI), a Fundação Roberto Marinho, o Instituto de Ensino e Pesquisa (INSPER), o Centro de Estudos, Pesquisas, Educação, Cultura e Ação Comunitária (CENPEC), o Instituo Alfa e Beto, o Instituo de Trabalho e Sociedade, a Fundação Itaú Social e a fundação Todos pela Educação. No meio destas discussões surgiu o Movimento pela Base Nacional Comum Curricular, gestando-se um ator coletivo composto por indivíduos, fundações e associações que galvanizaram interesses convergentes e passaram a ter forte gravitação na discussão sobre o tema.

A revisão de literatura permitiu identificar uma forte influência das experiências internacionais, das fundações empresariais e de organizações não governamentais neste processo, o que foi corroborado pela nossa pesquisa.

No âmbito nacional, fundações e ONGs já vinham ganhando espaço e força dentro do sistema educacional brasileiro, seja público ou privado, fornecendo materiais didáticos, cursos de formação, consultorias educacionais, serviços de gestão e organização do trabalho pedagógico. Estas não apenas aparecem no jornal como atores bastante citados, mas se destacam como atores que assinam matérias (quase um quarto delas), posicionando-se, decididamente a favor da BNCC. Os argumentos esgrimidos enfatizam que o currículo nacional reduzirá desigualdades sociais e culturais, garantirá o direito à educação, constituirá um projeto de nação para o país, e contribuirá a melhorar a formação de professores, os materiais didáticos e o processo de avaliação dos alunos. O único ponto criticado por estes atores foi o curto prazo de 
construção do documento e o fato da proposta não ser tão prescritiva e detalhada quanto eles esperavam. Ainda, estas organizações reafirmam a necessidade de articulação das políticas públicas PNE, BNCC e SNE com o fim de aperfeiçoar o controle do sistema, incluindo a fiscalização das instituições educacionais, os sistemas de avaliações e os programas de premiação para professores.

As experiências internacionais difundidas pelo jornal tendem a valorizar os resultados obtidos por outros países na implementação de um currículo nacional. Estas são especialmente tratadas nas matérias assinadas pelos jornalistas da Folha de São Paulo, que também tendem a supervalorizar a visão das fundações e ONGs. Assim, a visão de êxito dos currículos nacionais de países estrangeiros acaba reforçando, no jornal, a posição de fundações e ONGs.

No que respeita às perspectivas dos professores universitários da área da educação, o jornal publicou apenas uma matéria extensa, uma nota muito breve, e um artigo em coautoria entre um jornalista e uma professora. A primeira, escrita por Maria M. S. Malavasi, professora da Unicamp, tem um tom fortemente crítico à BNCC. A professora argumenta que o currículo proposto tenderá a engessar o conteúdo a ser trabalhado pelas escolas, questionando sua autonomia. Esse engessamento e padronização do conteúdo não se adequa, segundo Malvasi, a um país tão grande e diverso culturalmente como o Brasil. Mais ainda, afirma que a retirada de autonomia é um equivoco, pois países que detêm grande qualidade e sucesso educacional, como a Finlândia, se baseiam na autonomia das escolas. Outro ponto questionado é a formação de professores, sustentando que o MEC tem enorme responsabilidade no assunto ao autorizar cursos privados aligeirados e de qualidade duvidosa. $\mathrm{O}$ ensino de historia foi o assunto das outras duas peças, também críticas à proposta. Um colunista da Folha e a professora da USP Elaine Barbosa consideram que a versão de cultura que orienta a proposta curricular bane a temporalidade $\mathrm{e}$ a o processo de formação das sociedades ocidentais. No painel do Leitor, o professor Carlos G. Mota, professor emérito da USP, considera que a proposta retira dos alunos a possibilidade de entender estruturas e processos históricos que desembocam na situação atual das nações, culturas e sociedades.

Quanto aos professores universitários citados como atores, as perspectivas não foram consensuais. Alguns estiveram envolvidos com a elaboração do documento, e o defendem; outros colocam em questão alguns aspectos. Naercio
Menezes Filho, professor do Centro de Políticas Públicas do Insper questiona que a base peca por ser excessivamente ampla e, portanto, difícil de aplicar pelos professores. Para ele, o currículo nacional deveria ser um currículo mínimo. O curto prazo de elaboração da base curricular é outro ponto criticado. O professor da USP Luís Carlos de Menezes, que participou de sua elaboração como assessor, reconhece que "o esforço foi rápido demais". Por sua vez, o professor de direito da USP Virgílio Afonso da Silva se posiciona contra a inclusão do ensino religioso, argumentando que isso altera a laicidade do Estado e permite a ocupação de espaços públicos republicanos serem ostensivamente ocupados e controlados por igrejas. Novamente sobre o ensino de história, o professor Janine Ribeiro, após deixar o cargo de Ministro, se manifesta pela necessidade de incluir a historia da África, do Brasil e de outras regiões deixadas de lado por um currículo eurocentrista, mas alerta que a educação crítica não deve cair em ideologia. Marcia Ramos, da Universidade Estadual de Londrina, defende a versão do currículo de história proposto, argumentando que ele cumpre com os objetivos de ensino da disciplina, que são o respeito à diversidade e às pluralidades étnico-raciais, de gênero e religiosa. Assim, no geral, embora o jornal veiculasse algumas posições críticas da academia, não buscou fontes de informação que, no cenário acadêmico das publicações e eventos científicos, vinham questionando mais fortemente a construção da BNCC.

Novamente, ressaltamos a ausência de espaço no jornal para veicular os posicionamentos dos professores da educação básica e da rede pública de ensino.

\section{Considerações finais}

Neste artigo identificamos os atores e posicionamentos sobre o processo de construção da BNCC que foram divulgados pelo jornal Folha de São Paulo, um dos jornais mais influentes do país, ao longo do ano 2015. A pesquisa hemerográfica desenvolvida permitiu captar a visibilidade pública que o jornal trouxe para determinadas opiniões sobre esta política educacional em construção, e inferir, mediante a análise dos autores e atores presentes e seus argumentos, o sentido no qual o jornal orientou sua capacidade de formar a opinião pública.

Contextualizamos a discussão do currículo nacional na história educacional das últimas três décadas, desde a entrada em pauta do assunto na 

jornal Folha de São Paulo?

Constituição de 1988 e a LDB de 1996, a partir dos quais foram elaborados os PNC e as DCN na década de 1990. De acordo com autores como Silva (2015) e Fernandes (2015) esses documentos já haviam delineado um currículo nacional, que foi ainda mais reforçado pelas avaliações nacionais estandardizadas. Assim, a construção de um currículo nacional, novamente pautado em 2014 com a formulação do PNE, foi avaliado por alguns pesquisadores no âmbito do GT de Currículo da ANPED como uma tentativa de aumentar o controle do Estado sobre o processo educacional e dos docentes (MACEDO, 2015; GABRIEL, 2015; FREITAS, 2014).

Partimos de um conjunto de perguntas orientadas a identificar atores, interesses e posicionamentos nas matérias divulgadas pela Folha de São Paulo. Indagamos quais foram os principais atores cujas perspectivas sobre o currículo e a educação nacional foram divulgadas, a que segmentos sociais eles respondem e quais interesses representam. $\mathrm{O}$ exame das matérias permitiu corroborar o que a literatura já apontava: houve, na discussão do currículo nacional, um peso preponderante das ONGs, fundações e instituições vinculadas a interesses empresariais. Estas organizações e fundações, que vêm ganhando espaço no âmbito educacional nacional, foram autoras de um quarto das matérias publicadas, sendo o mais relevante autor após os próprios jornalistas. Além disso, foram o ator mais frequentemente citado nas matérias do jornal, sejam estas editoriais, colunas, etc.

Quanto a outros atores, destacaram-se os expertos internacionais, que apesar dessa denominação dada nas matérias, geralmente não tinham formação em educação. Professores universitários tiveram pouca presença como autores, mas foram consultados como fontes em várias matérias. Em fim, o MEC, e secretários estaduais de educação foram fontes com frequência consultadas nas matérias.

Quais foram as perspectivas sobre a BNCC publicadas no jornal? As matérias escritas pelos jornalistas da Folha, que constituíram a maioria, endossaram a proposta em construção mediante a valorização dos currículos nacionais implementados em outros países, assim como tenderam a veicular preferencialmente as visões das fundações e organizações empresariais. Não obstante fizeram alguns questionamentos, especialmente no que toca ao currículo da disciplina historia.

As fundações, ONGs e outras organizações empresariais, com destaque para o Instituto Unibanco/Itaú Social, Todos Pela Educação; CENPEC, Fundação Lemann; Movimento Pela Base; CNI; INSPER; Instituto Trabalho e Sociedade e Instituo Alfa e Beto, se colocaram firmemente a favor da BNCC, enfatizando que um currículo nacional tenderá a reduzir as desigualdades sociais e culturais, garantindo o direito à educação. Reforçaram também a necessidade de mudanças na formação de professores, nos materiais didáticos um mercado no qual já estão inseridas - e no processo de avaliação dos alunos, sugerindo a necessidade de novas avaliações em larga escala. Enfim, consideraram imprescindível a efetivação do SNE para unificar os sistemas educacionais. Claramente defenderam posições fiscalizadoras e meritocráticas para aperfeiçoar o controle do sistema educacional, atribuindo um papel importante aos sistemas de avaliação, ao controle das instituições educacionais e ao estabelecimento de programas de premiação para professores. As fundações e ONGs empresariais qualificaram a BNCC como um projeto de nação, atribuindo ao currículo, em sintonia com outras peças de política pública como o PNE e o SNE, o potencial de reduzir desigualdades sociais e elevar a qualidade do sistema educacional.

As perspectivas dos professores universitários da área de educação não foram consensuais. Apenas uma longa matéria assinada por uma professora criticou amplamente o processo de construção e os efeitos da BNCC. Questionamentos também surgiram sobre o ensino religioso e o ensino de historia, mas neste último caso, houve também argumentos endossando a proposta. Entretanto, as posições mais críticas da academia, que identificamos mediante a revisão de literatura, foram pouco divulgadas pelo jornal, que tendeu a não consultar esses pesquisadores como fontes de informação.

O jornal não cedeu espaço para veicular os posicionamentos dos professores da educação básica e da rede pública de ensino em nenhum momento. Trata-se de uma ausência bastante reveladora na medida em que são estes os que irão levar adiante uma mudança curricular no dia a dia da escola.

Ao começar a pesquisa nos perguntamos se houve equilíbrio na apresentação das perspectivas dos diversos atores envolvidos na BNCC. Os resultados mostram que não: um ator, as fundações e ONGs empresariais, que no processo conseguiram galvanizar vários grupos em torno do movimento 
Todos pela Educação, tiveram suas perspectivas mais divulgadas, tanto em matérias próprias como através das referências realizadas pelos jornalistas, que as consideraram fonte de informação privilegiada. O jornal também tendeu a visibilizar esse ator indiretamente, mediante a valorização de casos de sucesso de currículos nacionais implementados em outros países, estimulando a necessidade de adoção de uma política similar no país. Também o fez ao não consultar as fontes mais críticas dentro da academia e ao silenciar completamente os professores da educação básica. Ao adquirir esse viés na informação apresentada, o jornal se tornou um formador de opinião que representou os interesses específicos do empresariado e do setor financeiro.

Finalmente, procuramos verificar em que medida o jornal tinha exposto abertamente os debates e controvérsias suscitados. Embora algumas avaliações críticas da proposta curricular fossem divulgadas, tornar público um debate para a opinião pública teria requerido um tratamento mais igualitário das fontes, o que não ocorreu. Houve, inclusive, o silenciamento de alguns atores, como os próprios professores da educação básica. Foram registrados dois momentos de controvérsias, um em torno aos conteúdos do ensino de história, que foi tratado em seis matérias, incluindo duas assinadas por professores universitários e, embora controverso, o tema do ensino religioso foi pouco abordado, em apenas duas matérias.

Por fim, ponderamos que todo movimento de reforma curricular gera a ideia de mudança e modernização da educação, e de acordo com as perspectivas preponderantes expostas no jornal, se trata de mudanças positivas e, inclusive, salvacionistas. Entretanto, uma mudança curricular efetiva só acontece quando é pensada por todos e para todos.

\section{Notas}

1 Autor refere-se ao indivíduo que assina a matéria na publicação do jornal Folha de São Paulo; já o ator, é um indivíduo ou grupo que participou ativamente do processo de construção da BNCC. $\mathrm{O}$ ator não é necessariamente é autor, também tem suas perspectivas divulgadas no jornal ao ser citado nas matérias.

2 Trecho retirado da publicação do jornal Folha de São Paulo: "MALAVASI, Maria M. S. É equivoco tirar a autonomia das escolas. Folha de São Paulo. 17/09/2015”.

\section{Referências}

ABREU, C.B.M.; SILVA, M.R. Reformas para quê? As reformas educacionais nos anos 1990. Perspectiva, v.26, n.2, 2008, p. 523-550.

AIGENEREN, M. Análisis de contenido: una introducción. La Sociología y sus escenarios v 3, 1999, p. 1-52.

BARREIROS, D. Base Nacional Comum Curricular (BNCC): sujeitos, movimentos e ações poíticas. $38^{\circ}$ REUNIÃO NACIONAL DA ANPED, 01 a 05 de outubro de 2017, UFMA, São Luís, MA, 2017. Disponível em:

$<$ http://anais.anped.org.br/sites/default/files/arquivo s/trabalho_38anped_2017_GT12_227.pdf >. Acesso em: 20/02/2018.

BARDIN, L. Análise de conteúdo. Lisboa, Portugal: Edições 70.1977.

BRASIL. Constituição Federal. Brasília, DF. 1988.

LDB: Lei de Diretrizes e Bases da Educação Nacional. Lei No. 9394 de20 de dezembro de 1996, que estabelece as diretrizes e bases da educação nacional. 5. ed. Brasília, DF: Câmara dos Deputados, Coordenação Edições Câmara, 2010.

. Ministério da Educação. Base Nacional Comum Curricular. Brasília, DF. 2015. Disponível em: $<$ http://basenacionalcomum.mec.gov.br/documento/ BNCCAPRESENTACAO.pdf >. Acesso em: 07/05/2016.

. Plano Nacional de Educação 2014. Brasília, Câmara de Deputados, 2014a. Disponível em: http://www2.camara.leg.br/legin/fed/lei/2014/lei13005-25-junho-2014-778970-publicacaooriginal144468-pl.html. Acesso em 18/10/2017.

- Ministério de Educação. $O$ Sistema Nacional de Educação. Brasília, DF. Disponível em: http://pne.mec.gov.br/images/pdf/sase_mec.pdf. Acesso em:18/10/2017, 2014b.

CÓSSIO, M. F. Base Comum Nacional: uma discussão para além do currículo. Revista ECurriculum, v. 12, n. 3, 2014, p. 1570-1590. 
DOURADO, L. F. A formação de professores e a base comum nacional: questões e proposições para o debate. Revista Brasileira de Política e Avaliação da Educação v. 29, n.2, 2013, p. 367-388.

FERNANDES, C. O. Avaliação, currículo e suas implicações. Projetos de sociedade em disputa. Revista Retratos da Escola, v. 9, n. 17, 2015, p. 397-408.

FREITAS, L. C. Os Reformadores Empresariais da Educação. Educação \& Sociedade, v. 35, nº 129 , 2014, p. 1085-1114.

GABRIEL, C. T. Quando "nacional" e "comum" adjetivam o currículo da escola pública. Revista

Retratos da Escola, v. 9, n. 17, 2015, p. 283-297.

MACEDO, E. F. Parâmetros curriculares Nacionais: a falácia de seus temas transversais. In. MOREIRA, A. F. B et al (orgs). Currículo: Políticas e Práticas. Campinas: Papirus, 1988, p. 43-58.

MACEDO, E. F. Base Nacional Comum para Currículos: Direitos de aprendizagem e desenvolvimento para quem? Educação e Sociedade v36, n. 133, p. 891-908.

MALAVASI, M. M. S. É equívoco tirar a autonomia das escolas. Folha de São Paulo, São Paulo, 17/09/2015. Disponível em: <http://www1.folha.uol.com.br/fsp/cotidiano/23332 9eequivocotiraraautonomiadas escolas.Shtml>. Acesso em: 02/06/2016.

MOREIRA, A. F. Propostas curriculares alternativas: Limites e avanços. Educação \& Sociedade, a.XXI, n.73, 2000, p.109-138.
PEREIRA, F. B. A Constituição de uma Base Nacional Comum ou da base comum nacional. $37^{\mathrm{a}}$ REUNIÃO NACIONAL DA ANPED, 04 a 08 de outubro de 2015, UFSC, Florianópolis, 2015. Disponível em:

$<$ http://37reuniao.anped.org.br/wpcontent/uploads/2 015/02/P\%C3\%B4ster- GT12-4462.pdf>. Acesso em: 17/05/2016.

SCHENEIDER, M. P. Políticas de avaliação em larga escala e a construção de um currículo nacional para a educação brasileira. EccoS Revista Científica, n. 30,2013 , p. 17-33.

SEIBEL, E.J. Metodologia para pesquisa hemerográfica. Universidade Federal de Santa Catarina, 2013. Disponível em:

$<$ http://nipp.ufsc.br/pesquisas/tecnicas-de-pesquisanipp/pesquisa-hemerografica/> . Acesso em: 02/03/2016.

SILVA, M. R. Currículo, ensino médio e BNCC: um cenário de disputas. Revista Retratos da Escola v. 9 , n. 17,2015 , p. 367-379.

SILVA, T. T. Documentos de Identidade. Uma introdução às teorias do currículo. Belo Horizonte: Autêntica, 1999.

SÜNSSEKIND, M.L. As (im)possibilidades de uma Base Comum Nacional. Revista e-Curriculum v. 12, n. 3,2014 , p.1512 - 1529 .

TENA, A.; RIVAS-TORRES, R. Manual de Investigación Documental. México DF: Plaza y Valdés, 2007.

\section{Sobre as autoras}

Pricila de Fátima Stankevecz formou-se em licenciatura em pedagogia pela Universidade Federal do Paraná, atualmente estuda especialização em psicopedagogia institucional na Universidade Positivo no Paraná e especialização em políticas educacionais na Universidade Federal do Paraná.

Noela Invernizzi é professora do Setor de Educação e do Programa de Pós-Graduação em Políticas Públicas da Universidade Federal do Paraná, em Curitiba. Formou-se em Antropologia na Universidade da República, Uruguai, e fez mestrado e doutorado em Política Científica e Tecnológica na Universidade Estadual de Campinas. Fez estágio de pós-doutorado no Center for Science, Policy and Outcomes, na Universidade de Columbia, EUA. Pesquisa sobre as implicações sociais do desenvolvimento científico-tecnológico.

Recebido em novembro de 2017.

Aprovado em março de 2018. 
Anexo

Lista das matérias sobre a Base Nacional Curricular Comum pelo jornal Folha de São Paulo entre 1 de janeiro e 31 de dezembro de 2015

\begin{tabular}{|c|c|c|}
\hline TÍTULO DA MATÉRIA & AUTOR & VÍNCULO \\
\hline O Brasil precisa pôr a mão nas feridas & $\begin{array}{l}\text { Roberto Mangabeira } \\
\text { Unger }\end{array}$ & MEC \\
\hline Agenda urgente do Brasil & $\begin{array}{l}\text { Renato Janine Ribeiro, } \\
\text { Luiz Claudio Costa e } \\
\text { Binho Marques }\end{array}$ & MEC \\
\hline $\begin{array}{l}\text { Para avançar país precisa fortalecer } \\
\text { professores e melhorar administração }\end{array}$ & $\begin{array}{l}\text { Maria Helena Guimarães } \\
\text { de Castro }\end{array}$ & MEC \\
\hline Currículo sem pressa & Barry Mcgaw & Especialista convidado \\
\hline $\begin{array}{l}\text { Editorial sobre base Nacional foi equivocado, } \\
\text { diz leitor }\end{array}$ & Haroldo de Arruda & Leitor \\
\hline É equivoco tirar a autonomia da escola & Maria M. Sigrist Malavasi & Professor universitário \\
\hline $\begin{array}{l}\text { Historiador critica visão de história proposta } \\
\text { pelo MEC }\end{array}$ & Carlos Guilherme Mota & Professor universitário \\
\hline Andar para frente & Priscila Cruz & Todos Pela Educação \\
\hline $\begin{array}{l}\text { Não se pode usar Base Nacional como } \\
\text { receitinha }\end{array}$ & Priscila Cruz & Todos Pela Educação \\
\hline $\begin{array}{l}\text { Escolas precisam de padrões claros, diz } \\
\text { executivo do Instituto Itaú }\end{array}$ & Ricardo Henriques & Instituto Unibanco \\
\hline Preconceito na sala de aula & Ricardo Henriques & Instituto Unibanco \\
\hline A educação e os novos governantes & Ricardo Henriques & Instituto Unibanco \\
\hline Avanço para a educação Básica & $\begin{array}{l}\text { Denis Mizne e Camila } \\
\text { Pereira }\end{array}$ & Fundação Lemann \\
\hline Que plano o governo tem para a educação? & Maria Alice Setubal & CENPEC \\
\hline Educação prioridade das prioridades & Maria Alice Setubal & CENPEC \\
\hline $\begin{array}{l}\text { Mec lança portal para receber sugestões sobre } \\
\text { a Base Nacional Comum Curricular }\end{array}$ & Flávia Foreque & Colaboradora da Folha \\
\hline $\begin{array}{l}\text { Se o país fornecesse médicos como fornece } \\
\text { professores pacientes morreriam }\end{array}$ & Ana Estela de Sousa Pinto & Colaboradora da folha \\
\hline Base frágil & Folha de São Paulo & Colaborador da folha \\
\hline $\begin{array}{l}\text { Proposta do ministério que altera o ensino de } \\
\text { História causa reações }\end{array}$ & Sabine Righetti & Colaboradora da folha \\
\hline Um pouco de eurocentrismo & Hélio Schwartsman & Colaborador da folha \\
\hline $\begin{array}{l}\text { Brasil está desmoralizando a educação afirma } \\
\text { pesquisador }\end{array}$ & Rodrigo Russo & Colaborador da folha \\
\hline $\begin{array}{l}\text { Brasil criou bomba fiscal na educação diz } \\
\text { diretora do banco mundial }\end{array}$ & Fabio Takahashi & Colaborador da folha \\
\hline $\begin{array}{l}\text { Proposta do MEC para história mata } \\
\text { temporalidade }\end{array}$ & $\begin{array}{l}\text { Demétrio Magnoli e Elaine } \\
\text { S. Barbosa }\end{array}$ & $\begin{array}{l}\text { Colaborador da folha/ } \\
\text { professora universitária }\end{array}$ \\
\hline Currículo tem apoio mas resultado é incerto & Fabio Takahashi & Colaborador da folha \\
\hline $\begin{array}{l}\text { Mal avaliado, ensino médio poderá ter } \\
\text { currículo flexível }\end{array}$ & Flavia Foreque & Colaboradora da folha \\
\hline $\begin{array}{l}\text { Currículo engessado tira autonomia das } \\
\text { escolas diz professor da Unicamp }\end{array}$ & & Colaborador da folha \\
\hline
\end{tabular}




\begin{tabular}{|c|c|c|}
\hline & Adriano Queiroz & \\
\hline A hora e a vez do MEC & Folha de São Paulo & Colaborador da folha \\
\hline $\begin{array}{l}\text { Não se pode usar currículo nacional como } \\
\text { receitinha, diz diretora de ONG }\end{array}$ & Adriano Queiroz & Colaborador da folha \\
\hline Padrão para o ensino & Hélio Schwartsman & Colaborador da folha \\
\hline Currículo nacional critica ensino religioso & Flavia Foreque & Colaboradora da folha \\
\hline $\begin{array}{l}\text { Mercadante defende mais gramática no } \\
\text { currículo nacional }\end{array}$ & Fabio Takahashi & Colaborador da folha \\
\hline $\begin{array}{l}\text { Governo quer antecipar currículo nacional diz } \\
\text { ministro }\end{array}$ & Folha de São Paulo & Colaborador da Folha \\
\hline $\begin{array}{l}\text { Ministro diz querer antecipar projeto de } \\
\text { currículo nacional }\end{array}$ & Folha de São Paulo & Colaborador da folha \\
\hline $\begin{array}{l}\text { Flexibilização é urgente, decisão de São Paulo } \\
\text { é legitima }\end{array}$ & Folha de São Paulo & Colaborador da Folha \\
\hline $\begin{array}{l}\text { Especialistas analisam modelos de } \\
\text { administração escolar pelo mundo }\end{array}$ & Folha de São Paulo & Colaborador da Folha \\
\hline $\begin{array}{l}\text { Ensino médio não precisa de disciplinas } \\
\text { estanques }\end{array}$ & $\begin{array}{l}\text { Fabio Takahashi e Adriano } \\
\text { Queiroz }\end{array}$ & Colaborador da Folha \\
\hline $\begin{array}{l}\text { Monitorar alunos é a chave para o sucesso em } \\
\text { educação pelo mundo }\end{array}$ & Andrea Vialli & Colaboradora da Folha \\
\hline $\begin{array}{l}\text { Encontro busca lições nos melhores sistemas } \\
\text { de ensino }\end{array}$ & Fabio Takahashi & Colaborador da folha \\
\hline $\begin{array}{l}\text { Modelo para o Brasil, currículo australiano } \\
\text { demorou } 20 \text { anos para ficar pronto conta } \\
\text { professor }\end{array}$ & Fabio Takahashi & colaborador da folha \\
\hline $\begin{array}{l}\text { Currículo frágil é apontado como causa da } \\
\text { baixa qualidade no ensino médio }\end{array}$ & Fabio Takahashi & colaborador da folha \\
\hline O nó no ensino médio & Folha de São Paulo & colaborador da folha \\
\hline $\begin{array}{l}\text { Novo currículo nacional não deve mudar o } \\
\text { ENEM }\end{array}$ & Italo Nogueira & colaborador da folha \\
\hline $\begin{array}{l}\text { Disputas políticas, greves e cortes paralisam } \\
\text { ministro da educação }\end{array}$ & $\begin{array}{l}\text { Gustavo Uribe e Flávia } \\
\text { Foreque }\end{array}$ & colaborador da folha \\
\hline $\begin{array}{l}\text { Educadores veem excessos em nova base } \\
\text { curricular brasileira }\end{array}$ & $\begin{array}{l}\text { Ricardo Mioto e Rodrigo } \\
\text { Russo }\end{array}$ & Colaborador da folha \\
\hline Folha promove debate sobre a BNC & Folha de São Paulo & Colaborador da folha \\
\hline $\begin{array}{l}\text { Proposta do governo não inclui alfabetização } \\
\text { na Educação Infantil }\end{array}$ & Sabine Righetti & Colaboradora da folha \\
\hline $\begin{array}{l}\text { Em debate especialistas questionam prazo } \\
\text { para a base comum do ensino }\end{array}$ & Rodrigo Russo & Colaborador da folha \\
\hline Fissuras na base & Folha de São Paulo & Colaborador da folha \\
\hline $\begin{array}{l}\text { Ensino infantil precisa ter currículo claro, diz } \\
\text { assessor de educação Sueca }\end{array}$ & Fabio Takahashi & Colaborador da folha \\
\hline \multirow[t]{2}{*}{$\begin{array}{l}\text { Projeto curricular muito extenso não é } \\
\text { exclusivo do Brasil }\end{array}$} & Luiza Bandeira & Colaboradora da folha \\
\hline & & Colaborador da folha \\
\hline
\end{tabular}




\begin{tabular}{|l|l|l|}
\hline Educação fora da caixa & Folha de São Paulo & \\
\hline $\begin{array}{l}\text { MEC lança proposta que define 60\% do } \\
\text { currículo da educação Básica }\end{array}$ & Flávia Foreque & Colaborador da folha \\
\hline Ensino além da retórica & Folha de São Paulo & Colaborador da Folha \\
\hline $\begin{array}{l}\text { Australiano visita o Brasil e defende currículo } \\
\text { único para as escolas }\end{array}$ & Flávia Foreque & Colaborador da Folha \\
\hline $\begin{array}{l}\text { Ensino não pode ser de religião específica diz } \\
\text { conselho }\end{array}$ & Flavia Foreque & Colaborador da Folha \\
\hline $\begin{array}{l}\text { Definição de um currículo nacional causa } \\
\text { divergências no governo }\end{array}$ & $\begin{array}{l}\text { Flávia Foreque e Fábio } \\
\text { Takahashi }\end{array}$ & Colaborador da Folha \\
\hline
\end{tabular}

